\title{
Platinum-palladium loaded polypyrrole film electrodes for the electrooxidation of D-glucose in neutral media
}

\author{
İ. Becerik ${ }^{a}$, Ş. Süzer ${ }^{b}$, F. Kadırgan ${ }^{a, *}$ \\ a Istanbul Technical University, Department of Chemistry, 80626 Maslak-Istanbul, Turkey \\ ${ }^{\mathrm{b}}$ Bilkent University, Department of Chemistry, 06533 Bilkent-Ankara, Turkey
}

Received 9 April 1999; received in revised form 25 August 1999; accepted 3 September 1999

\begin{abstract}
Modified polymer films with metal particles incorporated into the films by electrodeposition are known as possible electrocatalysts for various electrode reactions such as fuel cell applications. This work presents some results concerning the electrooxidation of D-glucose at modified polymer film electrodes prepared on a platinum substrate. This reaction has a great deal of interest in view of its applications to detection systems (glucose sensor), fuel cells (pacemakers) and electroorganic systhesis. The modified polymer film electrodes contain platinum and/or palladium particles dispersed in the polypyrrole film by electrodeposition in neutral media. Addition of palladium to platinum modifies the electrocatalytic behaviour of the electrode drastically. The modification is thought to involve minimisation of the poisoning of the catalyst, hence increasing its electrode activity. (C) 1999 Elsevier Science S.A. All rights reserved.
\end{abstract}

Keywords: Polymer electrodes; Polypyrrole; D-glucose; Platinum/palladium particles

\section{Introduction}

Conducting polymers made from heterocyclic monomers have been the subject of intense research activity in recent years, on account of their high electroactivity with good reversibility and chemical stability for various electrochemical reactions [1]. Recently, many investigations have been reported on incorporation of catalyst particles onto a polymer electrode via electropolymerization [2-7]. The possibility of dispersing metallic particles inside these polymers gives electrocatalytically active electrodes, providing higher surface areas, where the organic molecules are oxidised. Metallic dispersion can be achieved by reduction of the appropriate metal salts. In particular, electrochemical deposition of platinum particles seems to be very useful because particles deposited distribute themselves three-

* Corresponding author. Fax: + 90-212-285-6386.

E-mail address: kadirgan@itu.edu.tr (F. Kadırgan) dimensionally in the layer, due to the high porosity of the polymer.

Polypyrrole (PPy) is a particularly attractive material for catalyst support because of its large surface area and high electrical conductivity and stability under conditions relevant to the operation of glucose fuel cells or sensors employing an aqueous neutral electrolyte [811]. This electrically conducting polymer allows the use of small amounts of platinum catalyst. In our previous work [12], we investigated the effect of platinum particles incorporated in polypyrrole films for D-glucose oxidation in phosphate media and determined the optimum conditions for minimum platinum loading and/or maximum current density. In order to obtain higher current densities at low oxidation potentials and so to be effective as the working anode in a glucose sensor or fuel cell, one needs to move onto bimetallic systems. In this report, new results are presented concerning the electrooxidation of D-glucose at modified platinum electrodes dispersed in PPy film after the addition of palladium to platinum by electrodeposition. 


\section{Experimental}

Electrochemical experiments were carried out using a classical experimental set-up consisting of a Wenking HP 88 high power potentiostat, a Tacussel GSTP 4 signal generator, a BBC Goerz Metrawatt X-Y recorder and a Nicolet 410 memory oscilloscope. Prior to any electrochemical preparation, a standard voltammogram was recorded to check the purity of the system. All experiments were performed at $25^{\circ} \mathrm{C}$, under a nitrogen atmosphere in a three electrode cell with the platinum electrode as the counter and the mercury $\mid$ mercurous sulfate $\mid \mathrm{K}_{2} \mathrm{SO}_{4}$ (sat) electrode (MSE) as the reference. A platinum sheet (geometric area: $1.45 \mathrm{~cm}^{2}$ ) was used as a substrate for the polymer film deposition. Experiments were performed mainly in a neutral medium $(\mathrm{pH}$ 6.8, $0.1 \mathrm{M} \mathrm{Na} \mathrm{NPO}_{4}+0.1 \mathrm{M} \mathrm{KH}_{2} \mathrm{PO}_{4}$ ). The electrolytic solutions were prepared from ultrapure water (Millipore Milli Q System) and Merck reagents. Pyrrole was purified by distillation under vacuum and was stored in the dark under a nitrogen atmosphere.

Electrodes were coated with polypyrrole films deposited by electrolysis at a constant potential $(+0.43 \mathrm{~V}$ (MSE)). The resulting film was washed with water. The thickness of the polymer layer was estimated as $0.2 \mu \mathrm{m}$ [13-15]. Platinum + palladium particles were incorporated into the polymer film by electrochemical deposition from solutions containing $2 \times 10^{-4} \mathrm{M}$ $\mathrm{H}_{2} \mathrm{PtCl}_{6}+10^{-3} \mathrm{M} \mathrm{PdCl}_{2}$ at a constant potential of $-0.56 \mathrm{~V}$ (MSE) and $\mathrm{pH} 6.8$ (buffered by phosphate ions). In order to ensure that comparable metals were deposited at platinum and platinum |palladium electrodes, the deposition process was carried out in such a way that the charge resulting from the complete reduction of the precursor salts was kept at $200 \mathrm{mC} \mathrm{cm}^{-2}$. This value corresponds to $100 \mu \mathrm{g} \mathrm{cm}^{-2}$ of platinum when platinum is the only metal deposited [16-18].

Surface characterisation using XPS (X-ray photoelectron spectroscopy) measurements was carried out using a Kratos ES3000 spectrometer with $\mathrm{Mg}-\mathrm{K}_{\alpha} \mathrm{X}$-rays at $1253.6 \mathrm{eV}$. Polymer coated (containing the dispersed metals as well) Pt electrode samples were inserted into the vacuum chamber (vacuum lower than $10^{-8}$ Torr) and analysed directly. A Jeol JSM-840 scanning microscope was also used for further characterisation of the metallic particle electrodes.

\section{Results and discussions}

\subsection{Oxidation of D-glucose on the Pt (substrate) / Ppy / Pt electrode}

The conditions of dispersion of the bimetallic electrocatalyst are critical in order to obtain comparable electrode surfaces. In our previous study we had investigated the effect of platinum deposition potential on the electrooxidation of D-glucose [12]. Values ranging from -0.36 to $-0.66 \mathrm{~V}$ (MSE) were tested for platinum deposition. The corresponding cyclic voltammograms after each deposition process in a solution containing $0.1 \mathrm{M}$ D-glucose in buffered solution with a sweep rate of $50 \mathrm{mV} \mathrm{s}^{-1}$ were recorded. The resulting catalytic activity was compared using the peak current densities of the anodic and cathodic oxidation peaks (A, B, C, D) of D-glucose. Maximum current density was obtained for $E_{\mathrm{dep}}$ : $-0.56 \mathrm{~V}$ (MSE), for peaks A, $\mathrm{B}, \mathrm{C}$. Hence, for preparation of bimetallic surfaces the same potential was used in order to compare and differentiate the effect of the secondary salts on the electrode surfaces. The deposition process was always carried out at $-0.56 \mathrm{~V}$ (MSE) in such a way that the charge resulting from the complete reduction was always $200 \mathrm{mC} \mathrm{cm}^{-2}$. The concentration of the solution of the secondary palladium salt was determined after systematic studies.

In Fig. 1a, we reproduced the voltammograms corresponding to the electrooxidation of D-glucose on a pure platinum and $\operatorname{Pt}($ substrate) $|\mathrm{PPy}| \mathrm{Pt}$ electrode (prepared as mentioned above) recorded at $50 \mathrm{mV} \mathrm{s}^{-1}$ in a phosphate buffered solution. The positive scans reveal three oxidation peaks at $-0.80 \mathrm{~V}$ (peak A),$-0.25 \mathrm{~V}$ (peak B) and $0.15 \mathrm{~V}$ (peak C) for a pure Pt electrode.
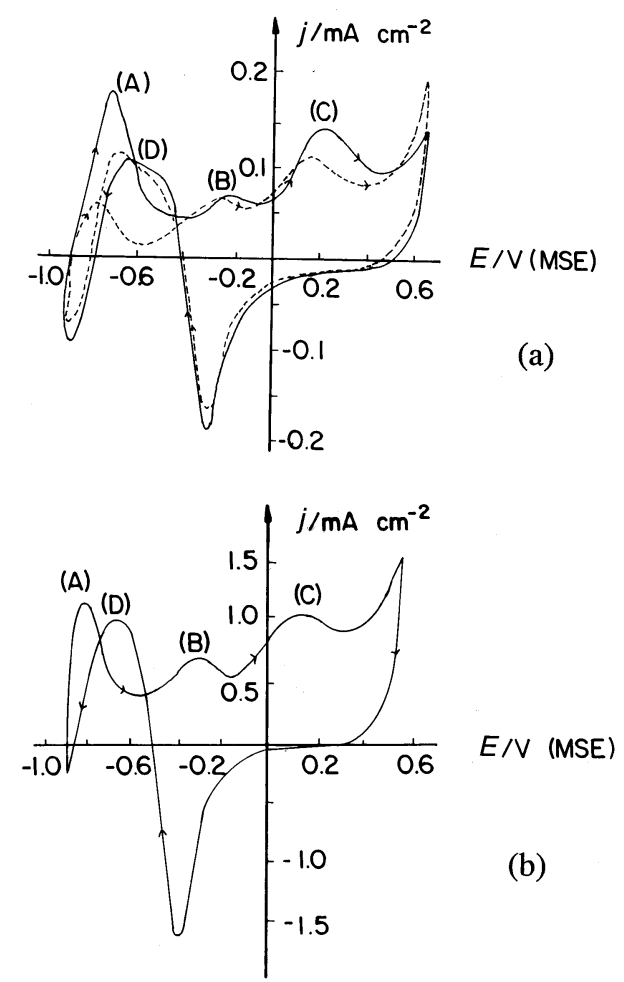

Fig. 1. (a) Voltammograms of $0.1 \mathrm{M}$ D-glucose on pure Pt electrode (dotted lines) and platinum modified polypyrrole electrode (solid lines). (b) Voltammogram on the platinum + palladium polypyrrole electrode (PPy $\mid \mathrm{Pt})($ note the current scales are different). 
Multiplicity of the anodic currents peaks may stem from the oxidation of dehydrogenated (peak A) glucose intermediate on the oxidized surface of the platinum. During the reverse scan, oxidation of D-glucose occurs in the potential range in which the surface oxides have been reduced. Oxidation of D-glucose on a PPy $\mid \mathrm{Pt}$ electrode recorded under the same conditions displays a similar shape. In comparison with the oxidation of D-glucose on a polycrystalline Pt electrode, the PPy $\mid \mathrm{Pt}$ electrode leads to higher activity for peaks A and C. A further effect on the oxidation current density of glucose after the incorporation of platinum in the PPy matrix proves the important role of the electrode structure for the electrocatalytic process [12].

SEM photomicrographs of polypyrrole film alone and platinum dispersed polypyrrole film are shown in Fig. 2a and $b$, respectively. While a porous film of polypyrrole is observed in Fig. 2a, platinum can clearly be seen as particles on the surface of the film in Fig. $2 b$. The platinum dispersed areas are darker than the underlying PPy due to the enhanced electron contrast resulting from the relatively high atomic number with respect to the polymer.

Since the thin polymer film is very porous, one may suspect that the Pt substrate may also play a catalytic role during the oxidation. In order to check whether there is any effect of the Pt substrate on the oxidation of D-glucose on a Pt dispersed PPy coated electrode, we carried out two types of experiments:

1. We recorded the surface sensitive XPS spectra of Pt(substrate) $\mid$ PPy and Pt(substrate) $\mid$ PPy $\mid$ Pt electrodes. The XPS spectrum of Pt $\mid$ PPy consisted of strong $\mathrm{C} 1 \mathrm{~s}, \mathrm{~N} 1 \mathrm{~s}$ and $\mathrm{O} 1 \mathrm{~s}$ peaks together with weaker impurity ones and no Pt peak could be observed. When Pt was electrodeposited, broad Pt4f and Pt4d peaks were observed as is shown in Fig. 3. Hence the surface of the Pt $\mid \mathrm{PPy}$ electrode is free from platinum and the surface contains platinum only after platinum salt is incorporated into the polymer film.

2. We checked the oxidation of D-glucose on a Pt dispersed PPy coated nickel substrate (Ni(substrate) $\mid$ PPy $\mid$ Pt electrode) and obtained a comparable current intensity in comparison to the Pt(substrate) $\mid$ PPy $\mid$ Pt electrode. These observations prove that substrate does not play a role in the electrooxidation of D-glucose on the polymer matrix [19].

3. We also checked whether there was a diffusion of D-glucose through the Pt $\mid$ PPy film and whether this was oxidised at the $\mathrm{Pt}$ substrate even when there was no Pt XPS signal arising from the Pt substrate. To illustrate the difference between both contributions we evaluated the true surface area of the $\mathrm{Pt}$ substrate and of the Pt $|\mathrm{PPy}| \mathrm{Pt}$ electrode from the
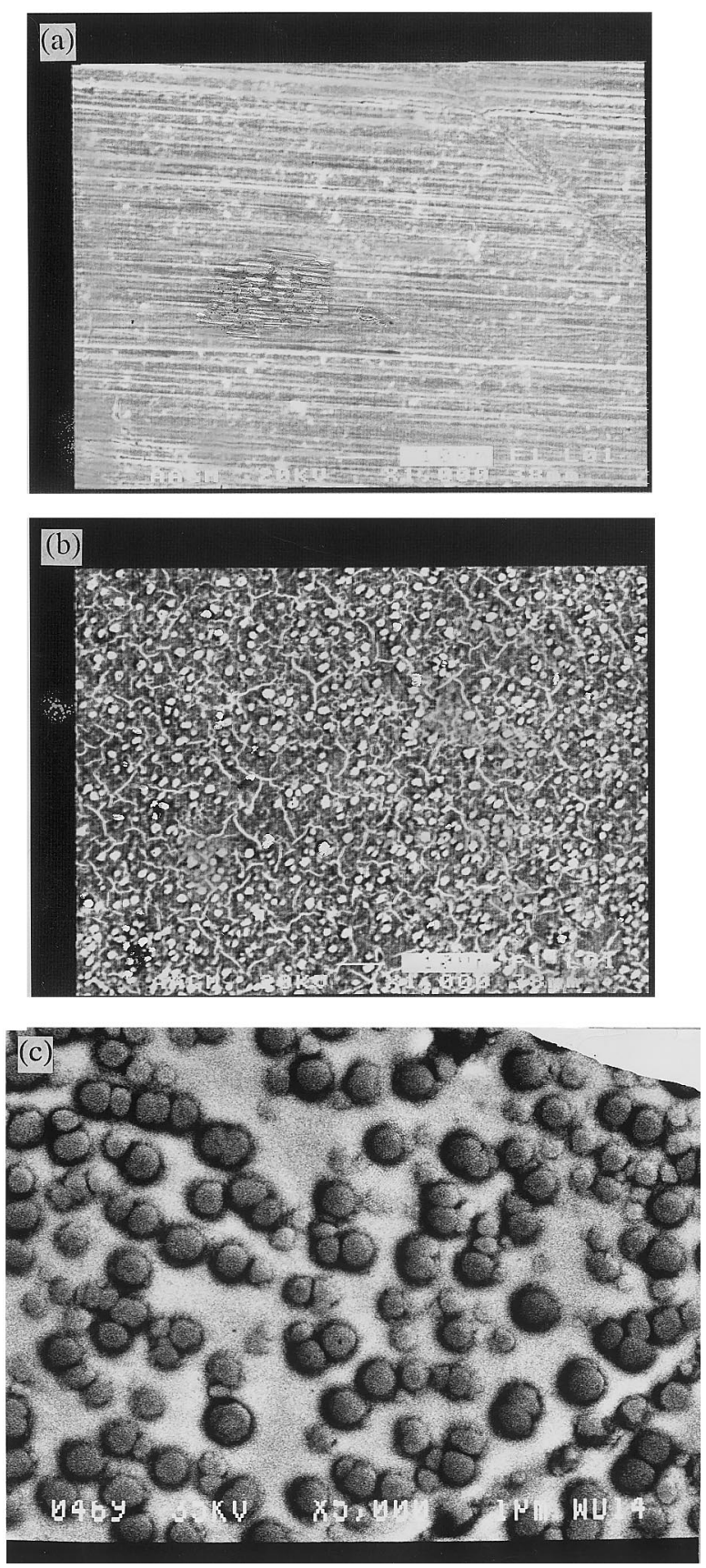

Fig. 2. (a) SEM of $\mathrm{Pt}$ (substrate) $\mid \mathrm{PPy}$; (b) SEM of $\mathrm{Pt}$ (substrate) $\mid$ PPy $\mid$ Pt electrode; (c) SEM of Pt(substrate) $\mid$ PPy $\mid$ Pt-Pd electrode.

oxygen adsorption region. The true surface area of the modified electrode is $26.5 \mathrm{~cm}^{2}$, while that of the Pt substrate is $14.5 \mathrm{~cm}^{2}$. The results obtained prove that the current density observed comes from the Pt $\mid$ PPy surface, since it is twice as high as the oxidation obtained on pure platinum. We have also studied the Ni(substrate) $|\mathrm{PPy}| \mathrm{Pd}$ electrode. We obtained comparable results with the Pt(substrate) $\mid$ PPy $\mid$ Pd system. 


\subsection{Oxidation of D-glucose on the Pt (substrate) $/ P P y / P d$ electrode}

Fig. $4 a-b$ shows the voltamogram of pure palladium and palladium dispersed PPy electrodes in $0.1 \mathrm{M}$ glucose aqueous buffered solution at room temperature $\left(20^{\circ} \mathrm{C}\right)$. The behaviour of both electrodes is obviously different since the pure palladium electrode is completely inactive in buffered neutral media, whereas the palladium dispersed electrode is reasonably electroactive in the same medium. While there is only a slight increase of current density on the PPy $\mid \mathrm{Pd}$ electrode at $0.05 \mathrm{~V}$ instead of peaks $\mathrm{B}$ and $\mathrm{C}$, seen on a platinum electrode, the peaks A and D are obtained with a lower current density relative to the Pt dispersed PPy electrode, giving the peak potential at more negative potential values.

\subsection{Oxidation of D-glucose on the \\ Pt(substrate) / PPy / Pt-Pd electrode}

The electrocatalytic activity of $\mathrm{Pt} \mid \mathrm{Pd}$ dispersed PPy electrodes is higher than both of the activity of $\mathrm{Pt}$ or $\mathrm{Pd} /$ dispersed PPy and pure Pt or Pd electrodes, leading to a synergistic effect. In Fig. 1b we display the voltammogram corresponding to the oxidation of D-glucose at a PPy $\mid \mathrm{Pt}-\mathrm{Pd}$ electrode which indicates a substantial increase of the intensities for all peaks (a 7-fold increase at peaks A and C, a 10-fold increase for peak B and an 8 -fold increase for peak D relative to the PPy $\mid \mathrm{Pt}$ electrode). The anticipated negative shift of the oxidation potentials is also observed except for the peak $\mathrm{D}$. The shift is $100 \mathrm{mV}$ for peaks $\mathrm{A}$ and $\mathrm{C}$ and $120 \mathrm{mV}$ for peak B. Herein, it is interesting to recall that $\mathrm{Pd}$, which prevents the formation of strong adsorbed intermediates according to the bifunctional theory, has a strong promoting effect on the dehydrogenation of organic molecules [20].

The presence of Pd on the surface was also checked by XPS. When the $\mathrm{Pt}-\mathrm{Pd}$ is electrodeposited, broad and overlapping Pt4f and Pd3d peaks were observed. Both the Pt $4 \mathrm{f}$ and $\mathrm{Pd} 3 \mathrm{~d}$ regions could be curve fitted to two spin-orbit doublets $\left(4 \mathrm{f}_{7 / 2}-{ }_{5 / 2}\right.$ and $\left.3 \mathrm{~d}_{5 / 2}-{ }_{3 / 2}\right)$ which were assigned to $\mathrm{Pt}(0), \mathrm{Pt}(4+)$ and $\mathrm{Pd}(0)$ and $\mathrm{Pd}$ $(2+)$, respectively as shown in Fig. 3 and tabulated in Table 1.

The SEM micrograph of PPy $\mid \mathrm{Pt}-\mathrm{Pd}$ (as shown in Fig. 2c) shows that $\mathrm{Pt}$ and $\mathrm{Pd}$ metal particles are dispersed on a porous polymer matrix causing a more active surface area, which is responsible for the higher catalytic activity.

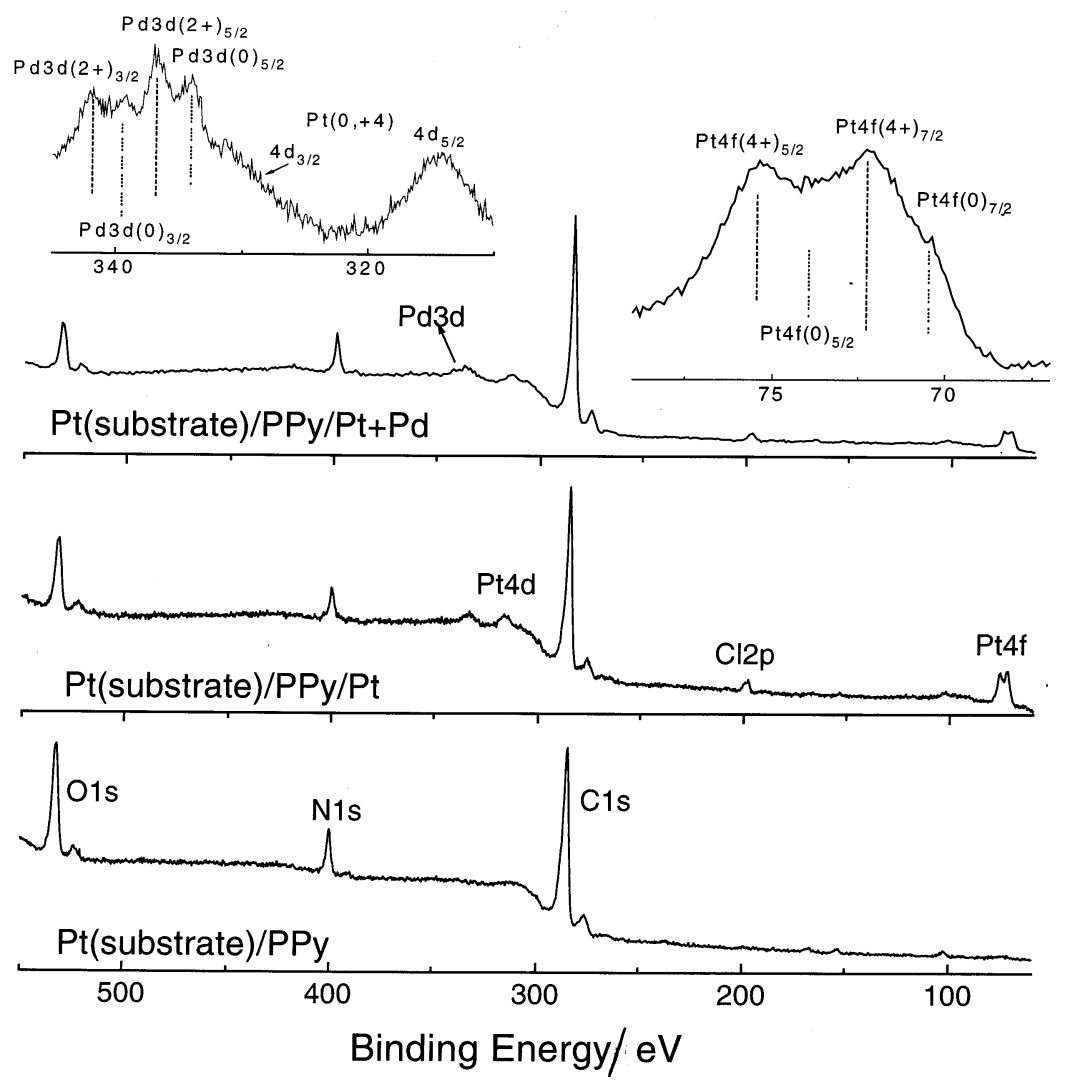

Fig. 3. XPS spectra of Pt(substrate) $\mid \mathrm{PPy}, \mathrm{Pt}($ substrate) $|\mathrm{PPy}| \mathrm{Pt}$ and $\mathrm{Pt}($ substrate) $|\mathrm{PPy}| \mathrm{Pt}+\mathrm{Pd}$ electrodes. Insert shows the enlarged Pt 4f and $\mathrm{Pd} 3 \mathrm{~d}$ regions where both oxidised and reduced metallic particles are identified. 

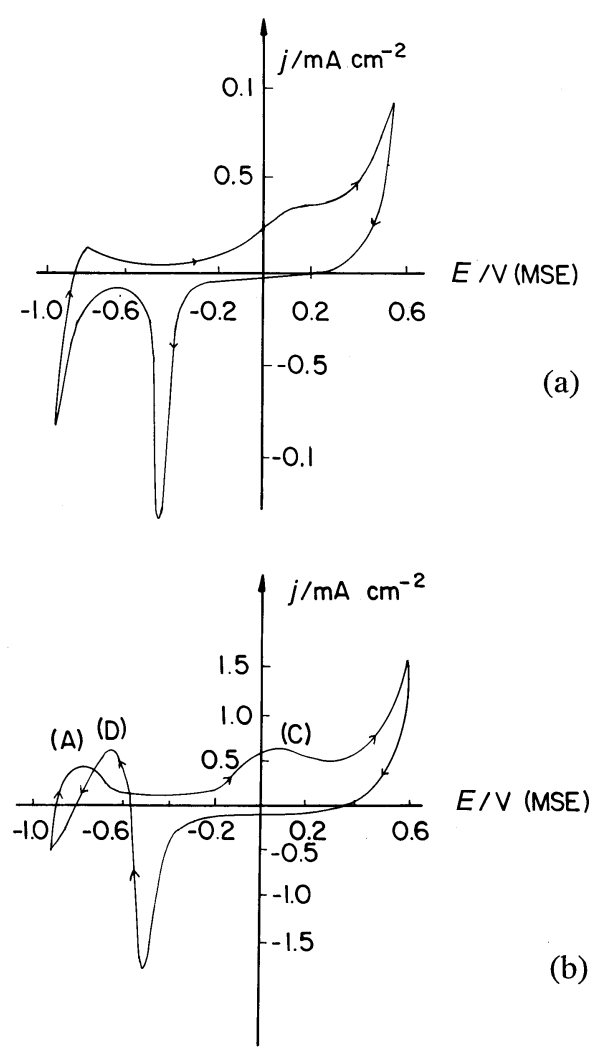

Fig. 4. (a) Voltammogram of $0.1 \mathrm{M}$ D-glucose on pure Pd electrode; (b) Voltammogram of $0.1 \mathrm{M}$ D-glucose on Pt (substate) $|\mathrm{PPy}| \mathrm{Pd}$ electrode.

Table 1

Measured binding energies of $\mathrm{Pt} 4 \mathrm{f}_{7 / 2}$ and $\mathrm{Pd} 3 \mathrm{~d}_{5 / 2}$ peaks in the $\mathrm{Mg}-\mathrm{K}_{\alpha}$ XPS spectra of electrodeposited platinum and platinum-palladium salts on polypyrrole coated platinum electrodes. Assignment of the various oxidation states was accomplished using Ref. [21]

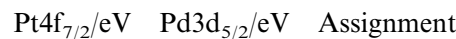
(Ref. [21])

\begin{tabular}{llll}
\hline $\operatorname{PPy} \mid \mathrm{Pt}$ & - & & \\
$\operatorname{Pt}($ substrate $)|\mathrm{PPy}| \mathrm{Pt}$ & 70.5 & & $\operatorname{Pt}(0)$ \\
& 72.2 & & $\operatorname{Pt}(4+)$ \\
$\operatorname{Pt}($ substrate) $|\mathrm{PPy}| \mathrm{Pt}-\mathrm{Pd}$ & 70.6 & & $\operatorname{Pt}(0)$ \\
& 72.3 & & $\operatorname{Pt}(4+)$ \\
& & 335.5 & $\operatorname{Pd}(0)$ \\
& & 338.2 & $\operatorname{Pd}(2+)$
\end{tabular}

\section{Conclusions}

The current densities obtained on a dispersed PPy electrode lead us to conclude that:

(a) Both Pd or Pt dispersed PPy electrodes show higher activities than the pure Pt or Pd electrodes. This may be explained by the higher surface area provided by the porosity of the PPy film. Increasing porosity allows the platinum or palladium particles to be deposited in a dispersed style giving the maximum possible surface area for the further oxidation of D-glucose.

(b) The experiments described above clearly demonstrated that highly dispersed electrodes composed of particles of platinum + palladium incorporated into the electrically conducting polypyrrole matrix exhibited enhanced activity toward the oxidation of D-glucose compared to the platinum-only electrode on a platinum substrate.

In the present state of our knowledge and investigations [22], three possible explanations may be invoked to interpret such effects:

(1) Modifications of electronic properties and collective surface properties by using metal particles on to the conductive polymer films; these films could lead to modification of electronic properties and collective surface properties.

(2) Enhancement of the overall reaction rate may be increased by shifting the electrode potential to more negative values.

(3) The presence of the second metal may favour the oxidation of the poisoning species at very low potentials via a bifunctional mechanism due to the $\mathrm{OH}$ species at the second metal surface which is necessary to oxidise D-glucose oxidation products. These $\mathrm{OH}$ species may cause the increase of current densities at peaks B and C. Previous investigations showed that peak A represents the dehydrogenation of the anomeric carbon and the larger catalytic action occurs with very small concentrations of metal ions in the bulk [23]. Secondary metals are supposed to occupy preferably the poisoning sites of the electrode, thus, enabling the surface to keep its activity much longer than when it is not modified.

This result may contribute not only to electrosynthesis of D-glucose oxidation products but also to design of better fuel cell or sensors.

\section{References}

[1] E.M. Genies, A. Boyle, M. Lapkowski, C. Tsintavis, Synthetic Metals 139 (1990) 207 and references therein.

[2] H. Haborde, J.M. Leger, C. Lamy, J. Appl. Electrochem. 24 (1994) 219.

[3] F.T.A. Vork, J.J. Janssen, E. Barendrecht, Electrochim. Acta 31 (1986) 1569.

[4] F.T.A. Vork, J.J. Janssen, E. Barendrecht, Electrochim Acta 32 (1987) 1187.

[5] K.M. Kost, D.E. Bartak, B. Kazee, T. Kuwana, Anal. Chem. 62 (1990) 151.

[6] A. Leone, W. Marino, B.R. Scharifker, J. Electrochem. Soc. 139 (1992) 438

[7] F. Fiçicioglu, F. Kadirgan, Electroanal. Chem. 430 (1997) 179.

[8] Y. Lin, G.G. Wallece, Electrochim. Acta 39 (1994) 1419.

[9] J.B. Schlenoff, H. Xu, J. Electrochem. Soc. 139 (1992) 2397. 
[10] A.F. Diaz, J. Bargon, Handbook of Conducting Polymers, vol. 1, Marcel Dekker, New York, 1986, p. 186.

[11] P.A. Christensen, A. Hamnett, Electrochim. Acta 36 (1991) 1263.

[12] I. Becerik, F. Kadirgan, J. Electroanal. Chem. 436 (1997) 189.

[13] P.A. Christensen, A. Hamnett, Electrochim. Acta 36 (1991) 1263.

[14] A.F. Diaz, J.J. Castillo, J. Chem. Commun. (1980) 397.

[15] E.M. Genies, M. Marchesiello, G. Bidon, Electrochim. Acta 37 (1992) 1015.

[16] W.T. Napporn, H. Laporde, J.M. Leger, C. Lamy, J. Electroanal. Chem. 404 (1996) 153.

[17] W.T. Napporn, H. Laporte, J.M. Leger, C. Lamy, J. Electroanal. Chem. 408 (1996) 141.
[18] H. Laborde, J.M. Leger, C. Lamy, J. Appl. Electrochem. 24 (1994) 1019.

[19] I. Becerik, F. Kadirgan, Electrochim. Acta, submitted for publication, 1999.

[20] I. Becerik, F. Kadirgan, Electrochim. Acta 37 (1992) 2651.

[21] D. Briggs, M.P. Seah, Practical Surface Analysis, Auger and X-Ray Photoelectron Spectroscopy, vol. 1, second ed., Wiley, Chichester, 1996.

[22] F. Kadirgan, B. Beden, J.M. Leger, C. Lamy, J. Electroanal. Chem. 125 (1981) 89.

[23] K.B. Kokoh, J.M. Leger, B. Beden, C. Lamy, Electrochim. Acta 37 (1992) 1333 and references therein. 